\title{
Türkiye'de 2000-2018 Yılları Arasında Örgün Eğitim Kurumları Kapsamında Cinsel Sağlık Eğitimlerine İlişkin Çalışmaların İncelenmesi ve Değerlendirilmesi ${ }^{1}$
}

\author{
DOI: $10.26466 /$ opus.922603 \\ *
}

\author{
Arzu Güçlü̈ $\underline{\text { Halis Özerk }}^{* *}$
}

* Sosyolog, Kent Üniversitesi, Lisansüstü Eğitim Enst. İstanbul/Türkiye

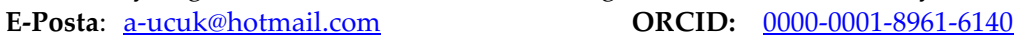

** Dr. Öğr. Üyesi, İstanbul Kent Üniversitesi Lisansüstü Eğitim Enstitüsü, İstanbul/Türkiye

E-Posta: halisozerk@halisozerk.com ORCID: $\quad$ 0000-0001-5530-6638

Öz

Bu çalışmanın amacı örgün eğitim kurumlarımız çerçevesinde 2000-2018 yılları arasında gerçekleştirilen cinsel sağlık eğitimlerine ilişkin akademik çalışmaların incelenmesi ve sonuçları bakımından değerlendirilmesidir. Betimsel tarama modeli kullanılan çalışmada alan yazın taraması sonucunda 2000-2018 yılları arasında gerçekleştirilen 32 çalışmaya ulaşılmıştır. Bunların 24' ü ulusal ve uluslararası hakemli dergilerde yayımlanan makale, 4'üdoktora tezi ve 4'ü de yüksek lisans tezidir. Çalışmalar içerik, amaç, yöntem ve bulgular açısından analiz edilmiştir. Ülkemizdeki çalışmaları karşılaştırabilmek amacıyla ayrıca yurt dışında bu konuda yapılan 13 çalışma araştırmaya dahil edilmiştir. Yurtdışı çalışmalarda farklı ülkelere (İtalya, Suudi Arabistan, Romanya, Çin, İran, Endonezya, Amerika, Brezilya, Meksika, Strbistan ve Ingiltere) yer verilmeye özen gösterilmiştir. Yapılan çalışmada sonucunda ülkemizdeki örgün eğitim kurumları kapsamında cinsel sağlık eğitimini içeren çalışmaların büyük çoğunluğunda (\%59.37) betimsel tarama yönteminin kullanıldı̆̆ görülmüştür. Çalışmalarda örneklem grubu olarak ilk sırada üniversite öğrencilerinin yer aldığg (\%44.4) bulgulanmıştır. Çalışmaların büyük çoğunluğunun öğrencilerin cinsel să̆lık konusundaki tutum ve davranışlarını tespit etmeye ve ilintili olarak da düzenlenen eğitimlerin cinsellikle ilgili bilgi ve tutumlarına etkisini ölçmeye yönelik olduğu görülmüştür. Çalışmalarda veli ve öğretmenlerin eğitimine ise çok düşük oranda yer verildiği saptanmıştır.

Anahtar Kelimeler: Ergenlik, Cinsel Eğitim, Ergenlerde Cinsellik.

\footnotetext{
${ }^{1}$ Çalışma, Arzu Güçlü' nün Klinik Psikoloji Yüksek Lisans bitirme projesi (2018-2019 yılı) çalışmasından türetilmiştir.
} 
ISSN:2528-9527

E-ISSN: 2528-9535

YIl Year: 11

Cilt Volume: 18

Sayı Issue: 39

Uluslararası Toplum Araştırmaları Dergisi

International Journal of Society Researches

Temmuz July 2021

Makalenin Gelis Tarihi Received Date: 19/04/2021

Makalenin Kabul Tarihi Accepted Date: 03/06/2021

\title{
The Evaluation and Investigation of the Sexual Health Education Given in Schools in Turkey Between the Years 2000-2018
}

\begin{abstract}
The purpose of this study is to investigate the academic studies done on the sexual health education given in schools in Turkey between the years 2000-2018 and to evaluate their results. The surveying of the body of literature using the descriptive survey method yielded 32 studies done between the years 2000-2018. 24 of these were peer reviewed articles published in national and international journals, 4 were doctoral thesis' and 4 were master's theses. The studies were analysed in terms of content, purpose, method and findings. 13 studies done abroad were also included in this study for the purpose of comparison with the ones done in Turkey. The studies done abroad were especially chosen from various different countries (Italy, Saudi Arabia, Romania, China, Iran, Indonesia, USA, Brasil, Mexico, Serbia and England). As a result of the study, it was seen that the vast majority (\%59.37) of studies done about the sexual health education given in schools in Turkey used the descriptive survey method. It was found that the leading (\%44.4) sample groups of studies consisted of university students. It was seen that the vast majority of studies intended to determine the attitude and behaviour of students on sexual health and to measure the effects of the organised education on their attitudes and knowledge on sexuality. It was determined that parent and teacher education was included in relatively very low amounts in the studies.
\end{abstract}

Keywords: Adolescence, Sexual Education, Sexuality of Adolescent. 


\section{Giriş}

Ergenlik fiziksel, zihinsel, kimyasal ve sosyal açılardan hızla değişen bireyin gelişme ve olgunlaşma süreçleriyle, çocukluktan erişkinliğe geçiş dönemidir (Santrock, 2014, s.16). Dünya Sağlık Örgütü (WHO, 2017), 1019 yaş aralığını ergenlik dönemi olarak tanımlamaktadır.

Türkiye İstatistik Kurumu (TÜİK)'nun 2018 yılı verilerine göre, 10-19 yaş arası nüfus 12764 690'dır. Bu toplam nüfusun \%15,6'sına denk gelmektedir.

Çok (2010, s.84)'a göre bedenin yetişkin özelliklerine dönüştüğü ve üreme yeteneğinin kazanıldığı ergenlik yıllarında yaşam boyu devam edecek cinsellik daha büyük önem kazanmaktadır.

Siyez ve Siyez, 2007)'e göre de cinsel açıdan olgunlaşan bedenlerine ve işlevlerine alışabilme, kendilerine özgü cinsel tutum ve değerlerini netleştirme, cinsellikle ilgili tutum, duygu ve yaşantılarını bütünleştirme gençleri bekleyen gelişimsel görevlerdendir. Bu görevlerini yerine getirme sürecinde ergenler, sosyal ve psikolojik desteğe her zamankinden daha fazla ihtiyaç duyarlar (Hurrelmann ve Quenzel, 2015). Ergenlik döneminde cinsel deneyimlerin yoğunluk kazanmasiyla cinsel sağlık eğitimi ihtiyacı ve önemi artmaktadır (Gürsoy ve Gençalp, 2010).

Nüfusbilim Derneği ve Birleşmiş Milletler Nüfus Fonu (2007), Türkiye: Gençlerde Cinsel Sağlık ve Üreme Sağlığı Araştırması sonuçlarına göre; ergen kız ve erkeklerin büyük bir kısmı ergenlikte büyüme ve gelişme sırasındaki değişimleri "endişe" olarak tanımlamaktadırlar.

T.C. Aile ve Sosyal Politikalar Bakanlığ 1 Aile ve Toplum Hizmetleri Genel Müdürlüğü Türkiye Ergen Profili Araştırması́nda (2013), katılımcılara cinsellikle ilgili bilgilerini ilk kimden öğrendikleri sorulmuştur. Katılımcların \%24'ü cinsellikle ilgili bilgilerini ilk annelerinden aldıklarını belirtmiştir. İkinci sırada arkadaşlar (\%19), üçüncü sırada ise okul (\%15) vardır. Cinsellikle ilgili hiç kimseden ya da hiçbir yerden bilgi almamış olanlar (\%42) dışarıda tutulduğunda ergenlerin yarıya yakınının (\%46) bu tür bilgileri 11-12 yaş aralığında aldığı görülmektedir. 
Cinsel bilgilerin ilk alındığı ortalama yaş 12 'dir. Cinsel sağlık eğitimi ile ilgili ebeveynlerin tutumlarını belirlemeye yönelik yapılan araştırmalar ilk bilgilerin anneler tarafından verildiğini ve sadece çocuk soru sorduğunda, utanarak kısa cevaplar verildiğini göstermektedir. Ancak anneler bu konularda bilgi seviyelerinin yetersiz olduğunu ve profesyonel bir kurum veya kişiden bilgi almadıklarını ifade etmişlerdir (Tuğrul ve Artan, 2001; Eroğlu ve Gölbaş1, 2005).

Akbaş ve Sanberk (2012), ortaöğretim kurumunda öğrenimine devam eden 437 öğrenci (233'ü kız ve 204'ü erkek) ile yaptıkları çalışmada, kız öğrencilerin ilk menstrüasyon (adet görme), erkek öğrencilerin ilk ejakulasyon (boşalma) deneyimini yaşadıkları sıradaki duyguları ile önceden hazırlıklı (bilgili) olma arasında anlamlı ilişki olduğunu tespit etmişlerdir.

Set, Dağdeviren ve Aktürk (2006) yaptıkları çalışmada ülkemizde cinsellik konusunun halen bir tabu sayıldığını, konuşulmaktan kaçınıldığını ve doğru bilgi edinmeye yönelik girişimlerin de sınırlı kaldığını belirtilmektedirler. Eroğlu ve Gölbaşı (2005) da cinsel konuların konuşulmaktan kaçınıldığı toplumlarda cinsellik hakkında sağlıklı bilgileri bireylere kazandırmak adına okullarda cinsel eğitim programlarının oluşturulmasının öneminin arttığını ifade etmektedir.

Georgetown Üniversitesi Üreme Sağlığı Enstitüsü'nde Igras ve diğerlerinin (2014) yaptığı genç ergenlerin cinsel ve üreme sağlığına yatırım yapmak konusundaki çalışmada dünya nüfusunun yarısının 1014 yaş arası çok genç ergenlerden oluştuğunu ve 1,2 milyar 10-19 yaş arası ergenin neredeyse \%90'ının düşük ve orta gelirli ülkelerde yaşadıklarını belirtmektedir. Bu ülkelerde istenmeyen gebelikler, anne ölümleri, güvensiz düşükler ve cinsel yolla bulaşan hastalıkların oranlarının çok yüksek olduğu tespit edilmiştir.

Kirby (2002), gençlerin cinsel davranışlarına okulun ve okul programlarının etkisini belirlemek için okullarda yapılan cinsel eğitim, erken gebeliği önleyici cinsel eğitim ve cinsel yolla bulaşan hastalıklar/ HIV odaklı müfredat tabanlı programları incelemiştir. Bu programların ortak saptanan sonuçları incelendiğinde cinsel ilişkiye girme yaşını geciktirdiği, sıklığını azalttığı, gebeliği önleyici yöntemlerin kullanımını arttırdığı, hamileliği ve erken doğum oranlarını azalttığı tespit edilmiştir. Araştırmanın sonucunda okulun ve okul müfredat tabanlı cinsel eğitim 
çalışmalarının ergenlerin riskli davranışlarda bulunmasını engellemek için kritik bir önemde olduğu vurgulanmıştır.

Hassan ve Creatsas (2000), cinsellik, üreme ve kontrasepsiyon hakkında bilginin ne yazık ki genellikle cinsel aktivite başladıktan sonra edinildiğini, bu nedenle hamileliğin ve cinsel yolla bulaşan hastalıkların önlenmesine sağlık hizmetlerinde ve eğitimde yüksek öncelik verilmesi gerektiğini belirtmektedirler. Çünkü gençlerin, özellikle yüksek oranda Cinsel Yolla Bulaşan Enfeksiyonların (CYBE) ve istenmeyen gebelik oranlarının cinsel sağlığa olumsuz sonuçlarına karşı savunmasız olduklarını prezervatif kullanımı da dahil olmak üzere daha yüksek cinsel eş değişimi oranları ve düşük kontrasepsiyon düzeyleri ile riskli cinsel davranışlarda bulunabildiklerini ifade etmektedirler.

Dünyanın dört bir yanındaki ergenlerin karşılaştığı bazı zorluklar arasında erken hamilelik ve ebeveynlik, doğum kontrolü ve güvenli kürtaj gibi zorluklar ve yüksek HIV/AIDS ve Cinsel Yolla Bulaşan Hastalık (CYBH) oranları bulunmaktadır. (Morris ve Rushwan, 2015).

WHO (2017), verilerine göre dünyada 36.9 milyon AIDS tanısı almış hasta bulunmaktadır ve Türkiye'de de 14.695 teşhis almış kayıtlı vaka belirtilmiş ve ülkemiz için artış hızı kritik olarak nitelendirilmiştir.

Fonner ve ark. (2014), düşük ve orta gelirli ülkelerde, okul temelli cinsel sağlık eğitimi ve HIV/AIDS önleme amaciyla yapılan 63 makalede yer alan 64 çalışma ile sistematik bir inceleme ve meta-analiz çalışması gerçekleştirmiştir. Meta-analizden elde edilen sonuçlar, okul temelli cinsel sağlık eğitiminin HIV/AIDS ile ilişkili riski azaltmada etkili bir strateji olduğunu göstermektedir. Okul Temelli Cinsel Sağlık Eğitimi Müdahaleleri öğrencilerin, HIV/AIDS hakkında bilgilere önemli oranda daha fazla sahip oldukları saptanmıştır.

İlgili yurtiçi araştırmalarda, ülkemizde gençler arasında cinselliğe dair yanlış inançlar ve mitlerin yaygın olduğu tespit edilmiştir (Kukulu ve diğerleri, 2009; Ejder Apay ve diğerleri, 2013). Cinsel yaşama başlama yaşı ile ilgili yapılan çalışmalarda ise ülkemizde giderek daha erken yaşlara inmeye başladığını göstermektedir (Gökengin ve diğerleri, 2003; Korkmaz Çetin ve diğerleri, 2008).

Ergenlerin çoğunun cinsellikle ilgili bilgi düzeylerini yetersiz olarak algıladıkları (Dağdeviren ve diğerleri, 2011; Pınar ve diğerleri, 2009; Civil ve diğerleri, 2010; Aslan ve diğerleri, 2014; Özcan ve diğerleri, 2016) ve 
cinsellik ve cinsel sağlıkla ilgili bilgileri gizli kapaklı, yetersiz ve yanlış kaynaklardan aldıkları tespit edilmiştir (Çetinkaya ve diğerleri, 2007; Kukulu ve diğerleri, 2009; Siyez ve Siyez , 2009; Çatık Yılmaz ve Başkan, 2014; Korkmaz Çetin ve diğerleri, 2008; Civil ve diğerleri, 2010).

Erkekler kızlarla karşılaştırıldığında ilk cinsel deneyimlerini daha erken yaşamışlar, daha çok partnerle ilişkiye girmişler ve korunma yöntemlerini daha az kullanmışlardır (Siyez ve Siyez, 2007; Aras ve diğerleri, 2005; Pınar ve diğerleri, 2009; Dağdeviren ve diğerleri, 2011). Cinsel yolla bulaşan hastalıklar ve aile planlaması hakkında yanlış bilgilerin doğru bildiklerinden daha fazla olduğu, erkeklerin bu konularda daha bilgisiz ve riskli davranışlara daha yatkın oldukları tespit edilmiştir (Topbaş ve diğerleri, 2003; Mağden ve diğerleri, 2003; Aras ve diğerleri, 2005; Siyez ve Siyez, 2009; Çatık Yllmaz ve diğerleri, 2014; Pınar ve diğerleri, 2009; Aslan ve diğerleri, 2014).

Gerek T.C. Aile ve Sosyal Politikalar Bakanlığı gerek TÜiK gerekse Türkiye'de yapılan çalışma bulgularına göre ergenlerin yarıya yakınının (\%42) cinsellikle ilgili bilgilerinin yeterli olmadığı, olanların da bu bilgileri en çok annelerinden aldıkları görülmektedir. Aynı kurumların verilerine göre annelerin cinsellikle ilgili bilgilerinin yetersiz olduğu ve var olan bilgilerini de bir kurum ya da profesyonel birinden almadıkları tespiti göz önünde bulundurulduğunda ergenlerin cinsellikle ilgili bilgi düzeylerinin oldukça yetersiz ve sağlıksız hatta hatalı olduğu aşikardır. $\mathrm{Bu}$ durumun, cinsellikle ilgili arzu edilmeyen sonuçları (istenmeyen gebelikler, erken ebeveynlikler, sağlıksız biçimde gebeliği sonlandırma girişimi nedeniyle ölümler) doğurması bakımından oldukça önemli bir problem olduğu da ortadadır.

Ergenlerin cinsellikle ilgili yetersiz, hatalı ve yanlış bilgilerine, aynı zamanda sağlıklı ve doğru bilgileri de almaları gereken yaşta almamalarına dayalı olarak ortaya çıkan problemlerin yaşanmaması (en azından minimum düzeye çekilebilmesi) için cinsel gelişim dönemleriyle uyumlu olacak şekilde sağlıklı ve doğru bilgileri almaları kaçınılmaz görünmektedir. Bu eğitimlerin ağırlıklı olarak verilebileceği ortamın da okullar olduğu konusunda gerek uluslararası kurum ve kuruluşlar gerekse araştırmacılar hemfikirdir.

Kapsamlı okul temelli cinsellik eğitimi, çocukların aileleri, dini ve toplum grupları ve sağlık profesyonellerinden aldıkları cinsellik 
eğitimini tamamlar ve güçlendirir (SIECUS, 2004). WHO (2017)'ya göre cinsellik eğitimi; cinselliğin bilişsel, duygusal, sosyal, etkileşimli ve fiziksel yönlerini öğrenme anlamına gelmektedir. Cinsellik eğitimi çocukluğun başında başlamakta ve ergenlik ve yetişkinlik döneminde ilerlemektedir. Çocuklar ve gençler için cinsel gelişmeyi desteklemeyi ve korumayı amaçlamaktadır.

Tüm çocuklar ve gençler yaşa uygun cinsellik eğitimine erişim hakkına sahiptir. Cinsel yolla bulaşan hastalıkları engellemek için gerekli olan bilgi ve becerilere duyulan, açıkça kabul edilmiş ihtiyaç, bu genel pozitif yaklaşımın ardından ikinci sırada gelmektedir. Dahası, cinsellik eğitimi uluslararası kabul gören insan haklarına, özellikle de hastalıkların önlenmesinin önüne geçen bilgi edinme hakkına dayanmalıdır (UNESCO,2015).

Gerek uluslararası kurum ve kuruluşların gerekse bilimsel çalışma sonuçlarına dayalı olarak araştırmacıların, ülkemiz de dahil olmak üzere, dünya genelinde erken ergenlik döneminin gelecekteki riskli davranışları engellemede kritik bir konumda olduğundan, bu dönemde özellikle cinsel eğitim programlarının uygulanmasının önemine vurgu yaptıkları görülmektedir. Aynı zamanda erken ergenlik döneminde sürdürülebilir eğitim programlarının oluşturulmasının ergenlerin vizyonlarını bütünsel hedeflerle genişletmek, odaklarını değiştirmek ve olumlu davranışlara teşvik etmek gelecek adına pozitif bir yatırım olarak ifade edilmektedir. Ergen ve üreme sağlığının, ülkelerin karşı karşıya kaldıkları yüksek risklere rağmen, tarihsel olarak göz ardı edildiği de vurgulanmaktadır.

Dolayısıyla bu çalışma, incelemesi ve değerlendirmesi yapılan çalışmaların sonuçlarının ortaya konulmasını ve buna dayalı olarak; tüm örgün eğitim kurumlarında erken ergenlik ve ergenlik dönemindeki bireylere, cinselliğe ilişkin sağlıklı ve doğru bilgileri kazandırabilmeyi sağlayacak çalışmaların planlanmasına katkıda bulunabilmeyi amaçlamıştır. İlintili olarak, cinsellikle ilgili erken ergenlik ve ergenlik döneminde cinsellikle ilgili olası sağlıksız ve olumsuz sonuçların mümkün olduğunca azaltılmasına katkıda bulunabilmeyi hedeflemiştir. 


\section{Bulgular}

Tablo 1. Çalışmaların Yıllara Göre Dağılımına İlişkin Frekans Dağılımı

\begin{tabular}{lll}
\hline Yayım Yilları & $f$ & $\%$ \\
\hline $2000-2003$ & 6 & 18,75 \\
$2004-2007$ & 8 & 25 \\
$2008-2010$ & 7 & 21,87 \\
$2011-2014$ & 7 & 21,87 \\
$2015-2018$ & 4 & 12,5 \\
Toplam & 32 & 100 \\
\hline
\end{tabular}

Tablo 1' e bakıldığında tez ve makalelerin \%25'inin 2004-2007 yılları arasinda, \%21,87'nin 2008- 2010 yılları 2011-2014 yılları arasinda, \%18,75'inin 2000-2003 yılları arasında 12,5'inin de 2015-2018 y1llar1 arasında yayınlandığı görülmektedir.

Tablo 2. Araştırma Yöntemine İlişkin Frekans Dağılımı

\begin{tabular}{lrc}
\hline Yöntem & $f$ & $\%$ \\
\hline Tam Deneysel & 6 & 18,75 \\
Yarı Deneysel & 5 & 15,62 \\
Betimsel tarama & 19 & 59,37 \\
Illişkisel tarama & 1 & 3,12 \\
Ölçek Geliştirme & 1 & 3,12 \\
Toplam & 32 & 100 \\
\hline
\end{tabular}

Tablo 2' ye bakıldığında; cinsel sağlık eğitimi konusunda yapılan araştırmalarda ağırlıklı olarak Betimsel Tarama $(\% 59,37)$ yönteminin tercih edildiği görülmektedir. Bunu \%18,75 oranında Tam Deneysel yöntemin izlediği, en az yapılan çalışma türünün ise \%3,12 oranında İlişkisel Tarama ve Ölçek Geliştirme yönteminin izlediği görülmektedir.

Tablo 3. Araştırmaların Örnek Grubuna Göre Dă̆ılımı

\begin{tabular}{lrc}
\hline Örneklem Grubu & $f$ & $\%$ \\
\hline İlköğretim & 6 & 16,6 \\
Ortaöğretim & 10 & 27,7 \\
Üniversite & 16 & 44,4 \\
Veliler & 2 & 5,5 \\
Öğretmenler & 1 & 2,7 \\
Okul Yöneticileri & 1 & 2,7 \\
Toplam & 32 & 100 \\
\hline
\end{tabular}


Tablo 3' a bakıldığında, Türkiye'de örgün eğitim kurumlarında yapılan cinsel sağlık eğitimi çalışmaları örneklemlerinin \%88,7'sini öğrencilerin oluşturduğu, öğrenci örnekleminde de ilk sırayı üniversite öğrencilerinin $(\% 44,4)$ aldığ görülmektedir. Bunu \%27,7 ile ortaöğretim öğrencileri takip etmiştir. Örnek grubunda okul eğitim-öğretim kadrosu (okul yöneticileri ve öğretmenler) \%5,4 oranındadır. Öğrenci velileri ile yapılan çalışmaların ise $\% 5,5$ olduğu görülmektedir.

Tablo 4. Örnekleme Tekniklerine İlişkin Frekans Dağılımı

\begin{tabular}{lrc}
\hline Örneklem Teknikleri & $f$ & $\%$ \\
\hline Amaca Uygun & 11 & 34,3 \\
Rastgele & 8 & 25 \\
Kolay (Ulaşılabilir) & 5 & 15,6 \\
Tabakalı & 3 & 9,37 \\
Evrenin Tamamı & 4 & 12,5 \\
Olasılıksız & 1 & 3,12 \\
Toplam & 32 & 100 \\
\hline
\end{tabular}

Tablo 4' te görüldüğü üzere, araştırmacılar genellikle seçilen örneklemin amaca uygun olmasına göre örneklemlerini belirlemişlerdir $(\% 34,3)$. Bunu \%25 ile rastgele örnekleme tekniği izlemektedir. En düşük düzeyde $(\% 3,12)$ başvurulan teknik ise olasılıksız örneklemedir.

Tablo 5. Araştırmalarda Ele Alınan Cinsel Sağlıkla Ilgili Konuların Frekans Dağılımı

\begin{tabular}{lcc}
\hline Konular & $f$ & $\%$ \\
\hline Ergenlerin Cinsellikle ilgili & 11 & 34,37 \\
Bilgi düzeyi ve tutumları & 5 & 15,62 \\
Cinsel Tutum ve Davranış Özellikleri & 4 & 12,5 \\
Hastalıklar Hakkında Bilgi Düzeyleri & 2 & 6,25 \\
Ebeveynlerin Cinsellik hk. Bilgi Düzeyi & 2 & 6,25 \\
Ergenlerin Cinsel Mitlere İnanma düzeyi & 1 & 3,12 \\
Erk. Ergenlerin Cinsel Deneyimleri & 1 & 3,12 \\
Erk. Ergenlerin Bilgi Kaynakları & 1 & 3,12 \\
Ergenlerin Cinsel Sağlık Arama Davranışı & 1 & 3,12 \\
Ergenlerin Toplumsal Cinsiyet Görüşleri & 1 & 3,12 \\
Cinsel Yaşam deneyiminde Roller & 1 & 3,12 \\
İlk Yaşantılar ve Psikososyal Faktörler & 1 & 3,12 \\
Cinsel Aktivite Eğilimleri & 1 & 3,12 \\
Cinsel Bilgi Testi Geliştirilme Çalışması & 32 & 100 \\
Toplam & & \\
\hline
\end{tabular}


Tablo 5' bakıldığında, 11 çalışmanın $(\% 34,37)$ cinsel sağlık eğitimi programının öğrencilerin cinsel sağlik bilgi düzeyleri ve tutumlarına etkisini belirlemek amacıyla yapıldığı görülmektedir. 5 çalışma $(\% 15,62)$ öğrencilerin cinsel tutum ve davranış özelliklerini belirlemek amaciyla yapılmıştır. Çalışmalardan 4'ü $(\% 12,5)$ öğrencilerin HIV/AIDS ve CYBH hakkındaki bilgi düzeylerini tespit etmeyi amaçlamıştır. Cinsel sağlık eğitimi konusunda ebeveynlerin görülerinin incelendiği 2 çalışma (\%6.25) mevcuttur. Çalışmalardan 2'si $(\% 6,25)$ öğrencilerin cinsel mitlere inanma düzeylerini belirlemek amacıyla yapılmıştır. Erkek öğrencilerin cinsel deneyimleri ve toplumdaki tabulara yönelik görüşlerini belirlemek için 1 çalışma $(\% 3,12)$ ve erkek ergenlerin cinsel davranış ve cinsel bilgi kaynaklarını değerlendirmek amacıyla 1 çalışma $(\% 3,12)$ yapılmıştır. Gençlerin cinsel sağlık arama davranışını etkileyen faktörlerin belirlenmesi amacıyla 1 çalışma $(\% 3,12)$ gerçekleştirilmiştir. Toplumsal cinsiyet rollerine ilişkin görüşlerini tespit etmek amacıyla 1 çalı̧̧ma $(\% 3,12)$, cinsel yaşam deneyimlerini bazı psiko-sosyal değişkenler açısından değerlendirilmesi için yapılan 1 çalışma (\%3.12) tespit edilmiştir. Ön bilgilerin ve ön yaşantıların cinsel tutum ve davranışlarla ilişkisinin incelenmesi amacıyla 1 çalışma (\%3.12) gerçekleştirilmiştir. Çalışmalardan 1 tanesi de (\%3.12) Türk ergenlerinin cinsel aktivite eğilimlerini tespit etmeyi amaçlamıştır. Son olarak cinsel eğitim programına dayalı cinsel bilgi testinin geliştirilmesi amacıyla 1 adet $(\% 3,12)$ çalışma yapıldığı görülmektedir.

\section{Sonuç ve Tartışma}

Türkiye'de 2000-2018 yılları arasında örgün eğitim kurumları kapsamında (kurum, öğrenci, öğretmen, okul yöneticisi, veli) cinsel eğitimle ilişkili yapılan çalışmaların ağırlıklı olarak $(\% 44,4)$ üniversite öğrencileriyle yapıldığı görülmüştür. İlköğretim öğrencileriyle yapılan çalışmaların ise \%16,6 düzeyinde olduğu görülmüştür.

İlköğretim olarak adlandırılan eğitimin sekiz yılı kapsadığı, bu yılların da genel olarak 6/7-14/15 yaşlarını içine aldığı düşünüldüğünde bu oranın oldukça düşük olduğu açıtır. Çünkü tüm gelişimsel kuramlara göre cinsel gelişim 6-7 yaşlarında başlamaktadır ve ergenlik döneminin başları (11/12 yaşları) cinsel kimliğin kazanılmaya başladığı 
ilk yaşlar olarak açıklanmaktadır. Dolayısıyla cinsel eğitimle ilgili çalışmaların (örgün eğitim bağlamında) ağırlıklı olarak ilköğretim düzeyinde gerçekleşmesi beklenirken bu oranın düşük olarak bulgulanması, cinsel eğitimle ilgili düşünce ve tutumların (dolayısıyla bilgi ve bilinç düzeylerinin) çoğu kurum ve kurum yönetimleri nezdinde yeterince gelişemediğiyle ya da öğrenci velilerinin cinsel eğitimle ilgili bilinç düzeylerinin yetersizliğine dayalı olarak gösterebilecekleri olası tepkilerden çekinilerek bu tür çalışmalara yetkililer tarafından izin verilmemesiyle açıklanabilir. Diğer taraftan 18 yaşına gelmemiş bireylerle ilgili yapılacak çalışmalarda veli muvafakatı (onamı) gerektiğinden yapılacak çalışmalara velilerin izin vermemesi nedeniyle çalışmaların oranı düşük kalmış olabilir. Örgün eğitim basamaklarından biri olan üniversitedeki öğrencilerin yaşının en az 18 olması dolayısıyla araştırmalara doğrudan kendilerinin onam vermeleri (araştırma oranının $\% 44.4$ olduğu hatırlanacak olursa), aynı zamanda gerek T.C. Aile ve Sosyal Politikalar Bakanlığı' nın gerek TÜIKK gerekse araştırma bulgularına göre ebeveynlerin cinsellikle ilgili bilgi düzeylerinin yetersizliği bu olasılığı pekiştirir niteliktedir.

Yapılan çalışmaların ağırlıklı olarak ergenlerin cinsel sağlık ve üreme sağlığ 1 konusundaki bilgi düzeyleri ve tutumlarını belirlemeye (5 çalışma) ve bu bağlamda verilen eğitimlerin bilgi düzeyi ve tutumlar üzerindeki etkilerini ölçmeye yönelik (6 çalışma) olduğu görülmüştür. $\mathrm{Bu}$ anlaşılabilir bir durumdur. Çünkü hangi konuda olursa olsun bir çalışmanın planlanabilmesi o konuda var olan durumun tespitini gerektirir. Aynı zamanda 6 çalışmanın, planlanmış ve programlanmış bir eğitimin, ergenlerin cinsel sağlık ve üreme konusundaki bilgi düzeyleri ve tutumlarına etkisi üzerine yapılması olumludur.

Şöyle ki, cinsel sağllk eğitimi uygulamalarının değerlendirilmesine yönelik örgün eğitim kurumlarında yapılan deneysel çalışmalar, öğrencilerin bilgi düzeylerini arttırmada ve cinsel sağlığa yönelik olumlu tutum geliştirmelerinde oldukça etkili olmuştur (Gölbaşı, 2002; Kutlu ve Çok, 2002; Selçuk, 2006; Şentürk, 2006; Pınar, 2008; Öztürk, 2013; Esen, 2015; Üstündağ, 2017). Özellikle akran liderliği ve grup rehberliğinin kullanıldığı cinsel sağlık eğitimi çalışmaları daha verimli olmuş ve öğrencilerden daha olumlu tepkiler alınmıştır (Kadığlu, 2005; Yöndem ve Güler, 2007; Kırmızıtoprak, 2007; Dağ ve diğerleri, 2012). 
Ancak çalışmalarda bu etkilerin olumlu sonuçları görülmesine rağmen halen T.C. Millî Eğitim Bakanlığı İlköğretim ve Ortaöğretim Kurumları müfredatında cinsel eğitimle ilgili bir dersin yer almaması veya cinsel eğitimle ilgili öğrenci, veli ve okul eğitim-öğretim kadrolarına yönelik eğitim programlarına (seminer, konferans, panel vb.) yeterince yer verilmemesi önemli bir eksikliği düşündürmektedir. Çünkü cinsel sağlık eğitimi alamamış ergenlerde riskli davranışlar görülme sıklığının artmakta olduğunu yapılan çalışmalar göstermekte HIV/AIDS ve CYBH hakkında bilgi eksikliği ve yanlış bilgilerin varlığına dikkat çekilmektedir. Özellikle bulaşma yolları ve korunma yöntemleri konusundaki eksik ve yanlış bilgiler sadece bireyleri değil tüm toplumu ilgilendiren fiziksel, psikolojik, sosyal ve ekonomik sorunlara neden olabilmektedir.

Bir halk sağlı̆̆ sorunu olan bu hastalıkların yayılmasının önüne geçebilmenin yolu ilköğretim döneminden itibaren cinsel sağlık eğitimi programlarının uygulanmasına bağlıdır. Cinsel yolla bulaşan hastalıklardan korunmak için kontraseptif yöntemler hakkında bilgi sahibi olmak ve bu bilgilerin mümkün olduğunca erken bir dönemde, risk alma davranışlarının arttığı ergenlik döneminden önce alınması gerekmektedir. $\mathrm{Bu}$ da ancak okul temelli cinsel sağlık eğitim programlarının tüm ülkeyi kapsayacak şekilde uygulanması ile mümkün olacaktır.

Alanda yapılan çalışmalar akran eğitimi yönteminin CSÜS ve CYBH konusundaki bilgi seviyesini arttırmada ve olumlu tutumlar geliştirmede etkili olduğunu göstermekte ve okul temelli yaklaşımlarda akran eğitimin kullanılması önerilmektedir. (Kırmızıtoprak, 2007; Çatık Yılmaz ve Başkan, 2014; Siyez ve Siyez, 2009; Topbaş, Çan ve Kapucu, 2003; Mağden ve ark., 2003).

Ergenlerin cinsellik ve üreme sağlığı ile ilgili bilgi kaynakları konusunda yapılan araştırmalar ilk bilgi kaynağı olarak aileyi göstermektedir. Anne bu konuda en çok tercih edilen bilgi kaynağ1 olarak belirtilmektedir. Annelere yönelik yapılan araştırmalar, çocukları ile bu konuları onlar soru sorumadan konuşmadıklarını, konuşurken utandıklarını ve cinsel sağlık konusunda bilgi seviyelerini yetersiz bulduklarını göstermiştir. Ayrıca anneler kendi bilgi eksikliklerini 
giderebilmek için bir uzmana başvurmadıklarını ve çocuklarını da yönlendirmediklerini belirtmişlerdir.

Bilgi kaynaklarından en çok tercih edilenlerden biri de porno filimlerdir. Buradan edinilen bilgilerin yapısı düşünüldüğünde sağlıklı ve doğru bilgi kaynaklarına ulaşılabilirliğin önemi ortaya çıkmaktadır. Ergenlerin önemli bir kısmı da bu konuları kimseyle konuşmamayı tercih ettiklerini ve bilgi almadıklarını belirtmişlerdir. Bütün bu araştırmalar cinsel sağlık konusunun halen bir tabu olarak görüldüğünü ve alanda uzman kişilere bilgi danışma konusunda bazı engellerin olduğunu göstermektedir. (Tuğrul ve Artan, 2001; Eroğlu ve Gölbaşı, 2005; Korkmaz Çetin ve ark., 2008)

Cinsel sağlık eğitimi programlarının etkinliğini değerlendirmek amacıyla yapılan çalışmalar, ergenlerin ihtiyaçlarını dikkate alan, katılımlarını teşvik eden, kültüre duyarlı olarak düzenlenmiş kapsamlı programların hem bilgi düzeyinde hem de tutumlar üzerinde çok olumlu etkileri olduğunu kanıtlamıştır. Eğitimlerin ergenlerin cinsel sağlığa, korunma yöntemlerine ve CYBH'lere ilişkin olumlu bir tutum geliştirmelerinde, karar verme becerileri kazandırmada, özsaygılarını arttırmada, iletişim becerilerinin gelişmesinde, farklı değerlere ve davranışlara karşı daha hoşgörülü davranabilmelerinde, toplumsal cinsiyet konusundaki kabulleri sorgulayabilmelerinde, ilk cinsel ilişkiyi ertelemelerinde ve riskli davranışlar yerine daha sorumlu davranışları seçmelerinde etkili olduğu tespit edilmiştir. Ayrıca cinsel istismar ve şiddetten kendilerini koruyabilmeleri konusunda da çok etkili olduğu saptanmıştır (Gölbaşı, 2002; Kutlu ve Çok, 2002; Kadıŏlu, 2005; Selçuk, 2006; Yöndem ve Güler, 2007; Pınar, 2008; Dağ ve ark., 2012; Öztürk, 2013; Esen, 2015).

Cinsel sağlık eğitim konusunda yurt dışındaki araştırmalar gelişmiş ülkelerde müfredat dahilinde uygulanan eğitim programlarının eksik yönlerinin bulunması ve geliştirilmesi amacıyla yapılmaktadır. Farklı kuramlara dayanarak oluşturulan cinsel sağlık eğitimi çalışmalarının okullarda uygulanması değerlendirilmesi ve sonuçlara dayanarak geliştirilmesi araştırmacıların temel çalışma çerçevesini oluşturmaktadır. Araştırma sonuçları, uygulanacak programların yeniden düzenlenebilmesi için politika belirleyicilere yol göstermektedir (Kirby 
ve ark., 2007; Andrade ve ark., 2009; Fonner ve ark., 2014; Rada, 2014; Drago ve ark., 2016; Lawrance ve ark., 2016; Castro ve ark., 2018).

Oysa gelişmemiş ve gelişmekte olan ülkelerde okul temelli cinsel sağlik eğitimi okul bünyesinde ulusal politika dahilinde yapılmamaktadır ve cinsellik bir tabu olarak görülmektedir. Bu da gençlerin cinsel bilgi ve tutumlarını etkilemekte, riskli davranışlarda bulunma oranını arttırmaktadır. Bu ülkelerdeki araştırmacılar çalışmalarında bu faktörlere, bu faktörlerin belirleyicilerine odaklanmak ve bunları araştırmak durumunda kalmaktadır. Cinsel sağlık eğitimi programlarının uygulanması sınırlı alanlarda kaldığı için ülke geneline etkisi olmamaktadır

Kirby ve ark. (2007), kapsamlı cinsel sağlık eğitimi çalışmalarının ortak özelliklerini belirlemek amacıyla 83 cinsel sağlık eğitimi uygulamasının değerlendirmesini içeren bir meta analiz çalışması gerçekleştirmiştir. Uygulamaların benzer yöntemleri kullananlar arasından seçilmesine ve ortak amaçlarının olmasına dikkat edilmiştir.

$\mathrm{Bu}$ amaçlar; cinsel yolla bulaşan hastalıkları ve HIV/AIDS engelleme, istenmeyen ve erken gebeliği önleme, doğum kontrol yöntemlerinin kullanılmasını arttırma, cinsellik konusunda kapsamlı bilgilendirme olarak belirlenmiştir. Yapılan analiz sonucunda araştırmacılar tarafından programların pozitif faktörleri belirlenmiş ve bunlar etkili cinsel sağlık eğitimi çalışmalarının özellikleri olarak sıralanmıştır.

- Cinsel sağlık eğitimi programı, alanında uzman bir ekiple ve farklı disiplinlerle iş birliği yapılarak oluşturulmalıdır.

- Hedef kitlenin var olan durumuna ve ihtiyaçlarına uygun olmalıdır.

- Sağlık hedefleri mantığa dayalı bir süreç kullanılarak belirlenmelidir.

- Programın İçeriğinin belirlenmesi aşamasında önceden planlanmış sağlık hedeflerine odaklanılmalıdır.

- Hedeflenen davranışların daha özel alt boyutları da araştırmaya eklenmelidir (Kondom kullanım1, cinsel perhiz vb.).

- Belirlenmiş çoklu risk ve koruyucu faktörlere odaklanmalıdır.

- Eğitime katılanların rahat edebileceği güvenli bir sosyal çevre oluşturulmalıdır.

- Programın içeriği kültüre, yaşa ve cinsel deneyime uygun olarak belirlenmelidir. 
- Bilimsel kurallara uygun bir yöntem izlenmeli, konuları mantık sirasinda vermelidir.

- Uygulama aşamasında yetkililerden gerekli destek alınmalıdır.

- Uygulayıcıların seçimine dikkat edilmeli, gerekli eğitim verilmeli, belirli aralıklarla izlenmeli, denetlenmeli ve gerektiğinde destek verilmelidir.

- Katılımcıların eğitimde kalmalarını engelleyecek faktörler ortadan kaldırılmalıdır. Gerekirse katılımcılara iş bulunmalı, çeşitli görevler verilmelidir.

- Eğitim programını pilot uygulaması mutlaka yapılmalıdır.

- Hedeflenen amaçlara yönelik etkinlikler planlanmalıdır.

- Katılımcıların bilgiyi kalıcı hale getirebilmeleri için interaktif bir öğretim yöntemi seçilmelidir.

- Etkinlikler planlanırken, eldeki kaynaklar ve katılımcıların değerlerine uygun olmasına özen gösterilmelidir.

- Cinsel davranışları etkileyen bireye özgü faktörler dikkate alınmalı ve bunlara yönelik öğretim yöntemleri kullanılarak hedeflenen değişiklik sağlanmalıdır.

\section{Öneriler}

- T.C. Millî Eğitim Bakanlığı bünyesinde İlköğretim Daire Başkanlığı ve Ortaöğretim Daire Başkanlığı bünyesinde, alandan akademisyenlerin de bulunduğu ortak bir komisyon kurularak; alanda yapılan araştırma bulgu ve sonuçlarından hareketle ve yaş düzeyinin gelişimsel özelliklerine dayalı olarak İlköğretim ve Ortaöğretim müfredatında tüm sınıflarda cinsel eğitime ilişkin bir derse yer verilebilir.

- T.C. Millî Eğitim Bakanlığı ile iş birliği içerisinde T.C. Aile ve Sosyal Politikalar Bakanlığı bünyesinde de benzer bir komisyon kurularak bakanlığa bağlı kurum ve kuruluşlar aracılığıyla anne-babalara yönelik, devamlılığı olacak şekilde eğitimler düzenlenebilir.

- T.C. Sağlık Bakanlığı tarafından tüm resmî, vakıf ve özel sağlık kurum ve kuruluşlarınca bulunulan il, ilçe, kasaba ve köylerde Gelişim Psikolojisi alanındaki psikologlarla iş birliği içerisinde ilgili sağlık alanı uzmanlarınca halka yönelik eğitimler düzenlenebilir. 
- Bir devlet politikası olarak, kitle iletişim araçlarında cinsel sağlık ve cinsel gelişim özelliklerine ilişkin eğitimlerin yer alması sağlanabilir.

- Devletin ilgili kurumları tarafından sivil toplum kuruluşlarının (çeşitli araçlarla teşvik edilerek) bu tür eğitimlerde yer almaları sağlanabilir.

- Bu eğitimlerin oluşturulmasında Kirby ve arkadaşlarının önerdiği ve sıraladığ1 eğitim çalışmalarının temel özellikleri dikkate alınabilir. 


\title{
EXTENDED ABSTRACT
}

\section{The Evaluation and Investigation of the Sexual Health Education Given in Schools in Turkey Between the Years 2000-2018}

\author{
Arzu Güçlü- Halis Özerk \\ Istanbul Kent University
}

Puberty is the period of time a physically, chemically, mentally and socially changing individual transitions from childhood into adulthood through processes of development and maturation. (Santrock, 2014:16) The World Health Organization (WHO) defines the age interval of 10-19 as puberty.

According to the 2018 data from The Statistics Institution of Turkey (TÜIK), there is a population of 12.764 .690 in the 10-19 age interval in Turkey. This approximately makes up 15.6 percent of the entire population.

According to developmental psychology theorists and researcher's sexuality, which is present for the rest of life after puberty, becomes more important during puberty as the body develops adult properties and gains reproductive ability. Because getting used to their sexually developing bodies and functions, getting clear about their sexual attitudes and values, combining their lives, emotions and sexual attitudes are some of the developmental tasks that await teenagers. In this period of completing tasks teenagers are in need of social and psychological support more than ever. This is why as sexual experiences get higher in intensity the need for and importance of sexual health education increases.

According to the results of the Demographics Society and United Nations Population Fund (2007), Turkey: Sexual Health and Reproductive Health in Teens Research the majority of teenage boys and girls define the changes in puberty during growth and development as "anxiety". 
In the Teen Profile in Turkey Research done by The Ministry of Family and Social Policies of The Republic of Turkey, Family and Social Services Department (2013) participants were asked from whom they learned about sexuality for the first time. 24 percent of Participants stated that they got their first information about sexuality from their mother. In second place came friends (\%19), and in third place was school (\%15). When the ones that weren't educated about sexuality anywhere or by anyone (\%42) are excluded it is seen that almost half of teenagers (\%46) got this information in the 11-12 age interval.

Difficulites like early pregnancy and parentage, contraception and safe abortion and high rates of HIV/AIDS and Sexually Transmitted Diseases (STDs) are some of the difficulties teenagers face all around the world.

According to the data from WHO (2017) there 39.9 million diagnosed AIDS patients in the world. In Turkey 14.695 diagnosed cases were declared and the rate of increase was defined to be critical.

Fonner and friends (2014) did a systematic meta-analysis and examination study using the 64 studies appearing in 63 papers done for the purpose of school based sexual health education and HIV/AIDS prevention in countries with low to middle income. The results from the meta-analysis suggest that school based sexual health education is an effective strategy for reducing HIV/AIDS related risk. It was determined that students exposed to School Based Sexual Health Education Interventions were significantly more educated about HIV/AIDS.

It was determined that the majority of teenagers viewed their knowledge level on sexuality to be insufficient (Dağdeviren and others, 2011; P1nar and others, 2009; Civil and others, 2010; Aslan and others, 2014; Özcan and others, 2016) and that they acquired information about sexual health from unreliable, insufficient and false sources. (Çetinkaya and others, 2007; Kukulu and others, 2009; Siyez and Siyez, 2009; Çatık Yılmaz and Başkan, 2014; Korkmaz Çetin and others, 2008; Civil and others, 2008)

According to the The Ministry of Family and Social Policies of The Republic of Turkey and the findings of studies done in Turkey nearly half of teenagers (\%42) don't have sufficient information on sexuality, and the ones that do get this information from their mothers. According 
to data from the same institutions, the mothers have insufficient information about sexuality and when the conclusion that they didn't get their existing information from an institution or a professional is considered it is obvious that the knowledge levels of teenagers are insufficient and unhealthy, even wrong. It is also obvious that this situation is an important issue in terms of producing undesirable situations related to sexuality (unintended pregnancy, early parentage, deaths due to unhealthy attempts at terminating pregnancies)

Therefore, this study intended to present the results of the examined and evaluated studies and through that contribute to the planning of practices with the purpose of teaching healthy and right information about sexual health to pre-teen and teenage individuals in all formal education institutions. Related to that, it also aimed to reduce the possible negative and unhealthy outcomes related to sexuality as much as possible in the early puberty and puberty periods.

In the study, using the descriptive survey model, 32 studies done between the years of 2000-2018 were reached through the scanning of the body of literature. 24 of these were articles published in peer reviewed national and international journals, 4 were doctorate theses, and 4 were master's thesis'. The studies were analyzed in terms of content, purpose, method and findings. To be able to compare the studies in Turkey, 13 studies done on this subject in other countries were included in the research. Care was taken to include studies from different countries (Italy, Saudi Arabia, Romania, China, Iraq, Indonesia, USA, Brazil, Mexico, Serbia and England). As a result of the study, it was seen that the majority of studies (\%59.37) on sexual health education in formal education institutions used the descriptive survey model. It was seen that college students were in first place (\%44.4) as the sample groups of these studies. The studies done with primary school students made up $\% 16.6$.

It was seen that most studies intended to determine the student's attitude and behaviour about sexual health and on a related note measure the effects of the organized educational sessions on their information levels and attitudes. It was also seen that the education of parents and teachers were mostly not included in the studies. 
The research on teenagers' sources of information about sexual and reproductive health show families to be the first source. It is stated that the mother is the most preferred source of information on this subject. Research directed at mothers showed that they did not talk to their children about these subjects without them asking, they felt embarrassed when talking and they found their knowledge level on sexual health to be insufficient. Mothers also disclosed that they did not consult a professional to overcome their lack of knowledge or direct their children to one. In the examination it was seen that teenagers stated that one of their most preferred sources of information on sexuality were porno movies. When the quality of the information gained from this source is considered the importance of the accessibility of healthy and reliable sources of information becomes evident.

In developed countries, research done on sexual education aims to detect and develop the shortcomings of the educational programs that are implemented as a part of the curriculum. In developing and underdeveloped countries however, school based sexual health education isn't done in school as a part of national policy but sexuality is seen as taboo. This affects teenagers' sexual knowledge and attitude, increasing their rates of engaging in risky behaviours. Kirby and friends (2007) did a meta-analysis study including 83 examinations of extensive sexual health education practices aiming to determine their shared properties and they determined the common objectives of the educational practices. These objectives were determined to be preventing STDs and HIV/AIDS, preventing unintended and early pregnancy, increasing the use of contraceptives and providing extensive information on sexuality.

It was concluded that, sexual health education, based on these common objectives, in formal education institutions being considered an educational policy and it being effectively implemented by all institutions is inevitable.

\section{Kaynakça / References}

Akbaş, T. ve Sanberk, İ. (2012). İlk menstrüasyon ve ejakülasyon deneyimi: hazırlık, ön yaşantılar ve ön bilgilerin cinsel tutum ve davranışlarla ilişkisinin incelenmesi. Ç. Ü. Sosyal Bilimler Enstitüsü Dergisi, 21(3), 323338. 
Andrade, H. H., Monteiro, S., Mello, M. B. D., Sousa, M.H., Makuch, M. Y., Bertoni, N. and Faúndes, A. (2009). Changes in sexual behavior following a sex education program in Brazilian public schools Mudanças no comportamento sexual de adolescentes de escolas públicas no Brasil após um programa de educação sexual. Cadernos de Saúde Pública, 25(5), 1168-1176.

Aras, Ş., Şemin, S., Günay, T., Orçın, E. ve Özan, S. (2005). Lise öğrencilerinin cinsel tutum ve davranış özellikleri. Türk Pediatri Arşivi, 40, 72-82.

Aslan, E., Bektaş, H., Başgöl, Ş., Demir, S. ve Vural, P. I. (2014). Üniversite öğrencilerinin cinsel sağlık konusundaki bilgi düzeyleri ve davranışları. Sted, 23(5), 174-182.

Birleşmiş Milletler Eğitim, Bilim ve Kültür Kurumu (UNESCO) (2015). Yapılandırılmış Cinsel Sağlık Eğitimi Küresel İnceleme http://sagliktagenc.org/zile/uploads/2018/01/UNESCO-

CSE Report 2015 Turkce.pdf, 06.05.2019.

Castro, F.D., Rojas-Martınez, R., Villalobos-Hernandez, A., Allen-Leigh, B., Breverman-Bronstein, A., Billings, D.L. and Uribe-Zuñiga, P. (2018). Sexual and reproductive health outcomes are positively associated with comprehensive sexual education exposure in Mexican highschool students. Plos One, 13(3), e0193780. doi: 10.1371/journal.pone.0193780.

Civil, B. ve Yıldız, H. (2010). Erkek öğrencilerin cinsel deneyimleri ve toplumdaki cinsel tabulara yönelik görüşleri. Dokuz Eylül Hemşirelik Yüksek Okulu Elektronik Dergisi, 3(2), 58.

Çaltık Yılmaz, A. ve Başkan, S. (2014). İlköğretim ve lise öğrencilerinin AIDS'e ilişkin bilgilerinin değerlendirilmesi. Güncel Pediatri, 1, 9-15.

Çetinkaya, S., Nur, N., Demir, Ö. F., Sönmez, S. ve Akan, S. (2007). Cumhuriyet Üniversitesi Sağlık Merkezi'nde verilen gençlik danışma birimi hizmetleri. Cumhuriyet Üniversitesi Trp Fakültesi Dergisi, 29(3), 104-108.

Çok, F. (2010). Ergenlerin cinsel eğitimi: Bir program denemesi. Ankara Üniversitesi Basımevi, Ankara.

Dağ, H., Dönmez, S., Şirin, A. ve Kavlak, O. (2012). Akran eğitiminin üniversite öğrencilerinin cinsel sağlık konusundaki bilgi düzeylerine etkisi. Anadolu Hemşirelik ve Sağ lık Bilimleri Dergisi, 15(1), 10-17.

Dağdeviren, N., Set, T., Aktürk, Z. ve Öztora, S. (2011). Sexual activity trends of Turkish Adolescents. Türkiye Klinikleri J Med, 31(4), 823-829. 
Drago, F., Ciccarese, G., Zangrillo, F., Gasparini, G., Cogorno, L., Riva, S., Javor, S., Cozzani, E., Broccolo, F., Esposito, S., Parodi, A. (2016). A survey of current knowledge on sexually transmitted diseases and sexual behaviour in italian adolescents. International Journal of Environmental Research and Public Health,13(4), 422.

Ejder Apay, S., Balcı Akpınar, R. ve Arslan, S. (2013). Öğrencilerin Cinsel Mitlerinin İncelenmesi. Anadolu Hemşirelik ve Sağlık Bilimleri Dergisi, 16(2), 96-102.

Eroğlu, K. ve Gölbaşı, Z. (2005). Cinsel eğitimde ebeveynlerin yeri: Ne yapıyorlar ne yaşıyorlar? Ankara Üniversitesi Hemşirelik Yüksek okulu Dergisi, 8(2), 12-21.

Esen, E. (2015). Lise öğrencilerine yönelik cinsel sağllk eğitimi programının geliştirilmesi, uygulanması ve değerlendirilmesi. Yayımlanmamış Doktora Tezi. Dokuz Eylül Üniversitesi Eğitim Bilimleri Enstitüsü, İzmir.

Fonner, V. A., Armstrong, K. S., Kennedy, C. E., O'Reilly, K. R. and Sweat, M. D. (2014). School based sex education and HIV prevention in low- and middle-income countries: A systematic review and meta-analysis. Plus One, e89692. doi: 10.1371/journal.pone.0089692.

Gökengin, D., Yamazhan, T., Özkaya, D., Aytuğ, S., Ertem, E., Arda, B. ve Serter, D. (2003). Sexual knowledge, attitudes, and risk behaviors of students in Turkey. Journal of School Health, 73(7), 258-263.

Gölbaşı. Z. (2002). Adölesan kızlara yönelik okula dayalı üreme sağhlğı eğitim programının etkinliği. Yayınlanmamış Doktora Tezi, Hacettepe Üniversitesi Sağllk Bilimleri Enstitüsü, Ankara.

Gürsoy, E. ve Gençalp, N. S. (2010). Cinsel sağlık eğitiminin önemi. Aile ve Toplum Eğitim Kültür ve Araştırma Dergisi, 6(23), 29-36.

Hassan, E. A. and Creatsas, G. C. (2000). Adolescent sexuality: A developmental milestone or risk-taking behavior? The Role of Health Care in the Prevention of Sexually Transmitted Diseases. Journal of Pediatric and Adolescent Gynecology, 13(3), 119-124.

Hurrelmann, K. and Quenzel, G. (2015). Lost in transition: Status insecurity and inconsistency as hallmarks of modern adolescence. International Journal of Adolescence and Youth, 20(3), 261-270.

Igras, S. M., Maceira, M. Murphy, E. and Lundgren, R. (2014). Investing in very young adolescents' sexual and reproductive health. Global Public Health, 9(5), 555-569. 
Kadıŏlu, H. (2005). Yetişkin ve akran liderli cinsel eğitimin ilköğretim 8.sinnf ögrencilerinin cinsellikle ilgili bilgi ve tutumları üzerindeki etkileri. Yayınlanmamış Doktora Tezi. Marmara Üniversitesi Sağlık Bilimleri Enstitüsü, İstanbul.

Kırmızıtoprak, E. (2007). Gençlerin cinsel yolla bulaşan hastalıklar ve güvenli cinsel yaşam konusunda bilgi ve davranıslarına akran eğitiminin etkisi. Yayınlanmamış Yüksek Lisans Tezi. Harran Üniversitesi Sağlık Bilimleri Enstitüsü, Şanlıurfa.

Kirby, D. (2002). The impact of schools and school programs upon adolescent sexual behavior. Journal of Sex Research, 39(1), 27-33.

Kirby, D., Laris, B. A. and Rolleri, L. A. (2007). Sex and HIV education programs: Their impact on sexual behaviors of young people throughout the world. Journal of Adolescent Health, 40, 206-217.

Korkmaz Çetin. S., Bildik, T., Erermiş, S., Demiral, N., Özbaşaran, B., Tamar, M. ve Aydın, C. (2008). Erkek ergenlerde cinsel davranış ve cinsel bilgi kaynakları: Sekiz yıl arayla değerlendirme. Türk Psikiyatri Dergisi, 19(4), 390-397.

Kukulu, K., Gürsoy, E. ve Sözer, G. A. (2009). Turkish university students' beliefs in sexual myths. Sexuality and Disabilty Journal, 27, 49-59.

Kutlu, Ö. ve Çok, F. (2002). Cinsel eğitim programına dayalı cinsel bilgi testinin geliştirilmesi. Eğitim ve Bilim Dergisi, 123, 3-12.

Lawrance, T. F., Akintobi, T. H., Miller, A., Archie-Booker, E., Johnson, T. and Evans, D. (2016). Assessment of a Culturally-Tailored Sexual Health Education Program for African American Youth. International Journal of Environmental Research and Public Health, 14(1),14.

Mağden, D., Şahin, S., Metin, F. ve Akkaya, F. (2003). Lise son sinıfa devam eden öğrencilerin AIDS hakkındaki bilgi düzeylerinin incelenmesi. Eğitim ve Bilim, 28(127), 31-36.

Morris, J. L. and Rushwan, H. (2015). Adolescent sexual and reproductive health: The global challenges. International Journal of Gynecology and Obstetrics, 131(2015), 40-42.

Nüfusbilim Derneği ve Birleşmiş Milletler Nüfus Fonu (2007). Türkiye Gençlerde Cinsel Sağlık ve Üreme Sağhlğı Araştırması (Özet Rapor). Damla, Ankara.

Özcan, H., Kızıkkaya Beji, N., Karadağ, A. ve Emlik, K. (2016). Üniversite öğrencilerinin üreme ve cinsel sağllğa yönelik bilgi düzeyleri. Uluslararası Hakemli Hemşirelik Araştırma Dergisi, 7, 83-97. 
Öztürk, B. (2013). Illköğretim 6. öğrencilerine yönelik cinsel eğitim programının etkililiğinin incelenmesi. Yayınlanmamış Yüksek Lisans Tezi. Dokuz Eylül Üniversitesi Eğitim Bilimleri Enstitüsü, İzmir.

Pınar, G. (2008). Üniversite gençlerine yönelik geliştirilen cinsel sağllk ve üreme sağlı̆̆ e ğitim programının etkinliği. Yayınlanmamış Doktora Tezi. Hacettepe Üniversitesi Sağllk Bilimleri Enstitüsü, Ankara.

Pınar, G., Doğan, N., Ökdem, Ş., Algier, L. ve Öksüz, E. (2009). Özel bir üniversitede okuyan öğrencilerin cinsel sağlıkla ilgili bilgi tutum ve davranışları. Tip Araștırmaları Dergisi, 7(2), 105-113.

Rada, C. (2014). Sexual behaviour and sexual and reproductive health education: A cross-sectional study in Romania. Reprod Health, 11, 48.

Santrock, John.W. (2014). Ergenlik. (14. Baskı). Didem Müge Siyez (Çev. Ed.). Nobel, Ankara. 2014.

Selçuk, Z. (2006). Ilköğretim 6. sinıf kız öğrencilerine uygulanan cinsel sağllk eğitiminin cinsel sağlık bilgilerine etkisinin incelenmesi. Yayınlanmamış Yüksek Lisans Tezi. Gazi Üniversitesi Eğitim Bilimleri Enstitüsü, Ankara.

Set, T., Dağdeviren, N. ve Aktürk, Z. (2006). Ergenlerde Cinsellik. Genel Tip Dergisi, 16(3),137-141.

Siyez, E. ve Siyez, D. M. (2007). Ergenlerin cinsel yaşam deneyimlerinin bazı psiko-sosyal değişkenler açısından incelenmesi. Türk Üroloji Dergisi, 33(1), 56-63.

Siyez, D.M. ve Siyez, E. (2009). Üniversite öğrencilerinin cinsel yolla bulaşan hastalıklara ilişkin bilgi düzeylerinin incelenmesi. Türk Üroloji Dergisi, 35(1), 49-55.

Şentürk, G. E. (2006). Ortaöğretim kurumlarına devam eden öğrenciler ile bu kurumda çalışan öğretmenler ve yöneticilerin cinsellikle ilgili yanlış bilgi ve inanışlarının belirlenmesi ve bir uygulama. Yayınlanmamış Yüksek Lisans Tezi. Marmara Üniversitesi Eğitim Bilimleri Enstitüsü, İstanbul.

Topbaş, M., Çan, G. ve Kapucu, M. (2003). Trabzon'da bazı liselerdeki adolesanların aile planlaması ve cinsel yolla bulaşan hastalıklar hakkındaki bilgi düzeyleri. Gülhane Tip Dergisi, 45(4), 331-337.

Tuğrul, B. ve Artan, İ. (2001). Çocukların cinsel eğitimi ile ilgili anne görüşlerinin incelenmesi. Hacettepe Üniversitesi Eğitim Fakültesi Dergisi, 20(141), 141-149. 
T.C. Aile ve Sosyal Politikalar Bakanlığı Aile ve Toplum Hizmetleri Genel Müdürlüğü (2013). Türkiye ergen profili araştırması 2013. https://ailevecalisma.gov.tr/uploads/athgm/uploads/pages/indirilebili r-yayinlar/68-turkiye-ergen-profili-arastirmasi-tepa-2013.pdf, 06.05.2029.

TÜIK (Türkiye İstatistik Kurumu) (2018). "Nüfus İstatistikleri", www.tuik.gov.tr/UstMenu.do?metod=temelist, 01.05.2019.

Üstündağ, A. (2017). Cinsel sağlık ve üreme sağlığı eğitiminin gençler üzerinde etkisinin değerlendirilmesi. Başkent University Journal Of Education, 4(1), 1-10.

WHO (World Health Organization) (2017). HIV/AIDS. https://www.who.int/en/news-room/fact-sheets/detail/hiv-aids, 03.05.2019.

World Health Organization (WHO). Mental health status of adolescents in South-East Asia: Evidence for action. New Delhi: Regional Office for South-East Asia; 2017. Licence: CC BY-NC-SA 3.0 IGO p:1

Yılmaz, D.V., Zeyneloğlu, S., Kocaöz, S., Kısa, S., Taşkın, L. ve Eroğlu, K. (2009). Üniversite öğrencilerinin toplumsal cinsiyet rollerine ilişkin görüşleri. Uluslararası İnsan Bilimleri Dergisi, 6(1), 775-792.

Yöndem, Z. D. ve Güler, S. (2007). Ergenlik ve cinsel sağlık eğitimi ile ilgili grup rehberliğinin 6.sınıf öğrencilerinin bilgi ve tutumlarına etkisi. İlköğretim Online, 6(1), 2-10.

\section{Kaynakça Bilgisi / Citation Information}

Güçlü, A. ve Özerk, H. (2021). Türkiye'de 2000-2018 yılları arasında örgün eğitim kurumları kapsamında cinsel sağlık eğitimlerine ilişkin çalışmaların incelenmesi ve değerlendirilmesi. OPUSUluslararası Toplum Araştırmaları Dergisi, 18(39), 958-982. DOI: 10.26466/opus.922603. 